\title{
PERFIL EPIDEMIOLÓGICO DOS PACIENTES TRANSPLANTADOS RENAIS EM HOSPITAL UNIVERSITÁRIO E O CONHECIMENTO SOBRE USO DE DROGAS IMUNOSSUPRESSORAS
}

\author{
Epidemic profile of kidney transplanted patients in a university hospital and the knowledge on the use \\ of immunosuppressive medication
}

Joanita Marques da Silva1', Ana Virginia de Melo Fialho², Maria Cristina Leite Araujo Borges ${ }^{1,2}$, Lucilane Maria Sales da Silva²

\begin{abstract}
RESUMO
Introdução: Transplante significa a cirurgia realizada em pacientes com problema grave e irreversível em um órgão ou tecido, recebendo outro saudável de um doador vivo ou com morte encefálica. Não significa a cura, mas a possibilidade de uma nova perspectiva de vida, porém exige a adesão a uma terapêutica em longo prazo, o acompanhamento multiprofissional contínuo e uso de medicações imunossupressoras. Objetivos: Conhecer o perfil epidemiológico dos pacientes atendidos no ambulatório de transplante renal, verificar o tempo médio de espera em hemodiálise até o transplante renal em um hospital de referência e investigar o conhecimento dos pacientes transplantados sobre a importância do uso de medicações imunossupressoras. Métodos: Pesquisa exploratória, descritiva com abordagem quantitativa realizada no ambulatório de transplante renal de um hospital universitário na cidade de Fortaleza-Ceará. A população foi de 84 pacientes de ambos os sexos, que receberam um rim entre janeiro de 2008 a abril de 2009. A amostra constituiu-se dos 25 pacientes que se enquadraram nos critérios de inclusão. Os dados foram coletados após a autorização do comitê de ética em pesquisa da Universidade Federal do Ceará (027.04.09) através de formulário composto de perguntas abertas e fechadas e analisado por tabelas e gráficos. Resultados: Não houve mudança no perfil dos pacientes atendidos pelo ambulatório em comparação com estudos anteriores. O tempo de espera até o transplante é longo, exigindo que o paciente permaneça em hemodiálise. Conclusões: O número de doações intervivos ainda é pequeno (20\%) e os pacientes referem conhecer a importância do uso dos imunossupressores, embora nem sempre sigam o tratamento à risca.
\end{abstract}

Descritores: Perfil Epidemiológico; Transplante Renal; Imunossupressores.

\section{Instituições:}

1. Serviço de Enfermagem do Hospital Universitário Walter Cantídio (HUWC). Universidade Federal do Ceará. Fortaleza- CE, Brasil

2. Mestrado Acadêmico em Cuidados Clínicos em Saúde. Universidade Estadual do Ceará (UECE). Fortaleza, CE. Brasil.

\section{Correspondência:}

Maria Cristina Leite Araujo Borges

Av. Visc. do Rio Branco, 2125 / 403, CEP 60.055-171, Fortaleza, CE, Brasil

Tel: (85) 3366-8363

E-mail: mcristinaborges@hotmail.com

\section{INTRODUÇÃO}

Transplante de órgãos ou tecidos significa a cirurgia realizada em pacientes com problema grave e irreversível em um determinado órgão ou tecido do corpo, recebendo outro saudável de um doador vivo ou com morte encefálica. ${ }^{1}$

Hoje no Brasil existem aproximadamente 35.000 doentes com insuficiência renal em tratamento dialítico, e, desses, somente 3.000 conseguem ser transplantados. A mortalidade chega a $20 \%$ dos pacientes em diálise, antes mesmo de ser realizado o procedimento. O Brasil é o segundo país em número de transplantes, ficando atrás apenas dos Estados Unidos. ${ }^{2}$

Apesar de ser um importante recurso terapêutico, a cirurgia não significa a cura, mas sim a possibilidade de uma nova perspectiva de vida e tratamento que vai incluir o acompanhamento médico contínuo, o uso de medicação imunossupressora e a adesão a um plano de cuidados com vistas à manutenção da saúde.

Alguns pacientes habituam-se aos inúmeros medicamentos que precisam tomar diariamente, mas outros têm dificuldade em aderir à rotina e aos horários sistemáticos. ${ }^{3}$ Não obstante as inovações nos imunossupressores para melhorar a qualidade de vida dos transplantados, ainda existe dificuldade na adesão a essas medicações. ${ }^{4}$ 
A rejeição tem sido uma das causas da perda do enxerto, pois mesmo recebendo orientação e acompanhamento rigoroso, muitos doentes acreditam que após a cirurgia não haverá a necessidade do uso continuo de medicamentos, devido ao mais importante já haver acontecido, ou seja, a realização do transplante. ${ }^{4}$

Os riscos de rejeição tornam fundamental a realização do acompanhamento ambulatorial, com o objetivo de prevenir complicações que possam comprometer a sobrevida do enxerto. O paciente e a família devem ser orientados acerca desse acompanhamento. Orientações sobre dieta, medicação, exercícios, prevenção de infecções e identificação de sinais e sintomas de rejeição são de extrema importância para o sucesso do tratamento. ${ }^{5}$

Nesse cenário, merece destaque a atuação dos médicos e enfermeiros, pois são os que atuam diretamente nos cuidados desses pacientes, desde a seleção e preparação do receptor até o período pós-transplante. Esses profissionais devem trabalhar juntamente com o paciente e a família assegurando-lhes a compreensão do estado geral de saúde desde o diagnóstico pré-transplante até a necessidade do acompanhamento ambulatorial pós-transplante..$^{5,6}$

\section{OBJETIVOS}

Conhecer o perfil epidemiológico dos pacientes atendidos no ambulatório de transplante renal e submetidos a transplante no período de janeiro de 2008 a abril de 2009, verificar o tempo médio de espera em hemodiálise até o transplante renal em um hospital de referência e investigar o conhecimento do paciente transplantado sobre a importância do uso de medicação imunossupressora.

\section{MÉTODOS}

Trata-se de uma pesquisa exploratória e descritiva com abordagem quantitativa. Foi realizada no ambulatório de transplante renal de um hospital universitário na cidade de Fortaleza-Ceará, cadastrado como centro transplantador renal pela Central Nacional de Transplante do Ministério da Saúde. A escolha deu-se por ser um serviço de referência estadual e pela facilidade de acesso.

A população foi composta por pacientes de ambos os sexos que receberam órgão de doador vivo ou falecido, perfazendo um total de 84 transplantados de janeiro de 2008 a abril de 2009. A amostra foi constituída por pacientes que se enquadravam nos seguintes critérios: idade acima de dezoito anos, tempo de transplante de até dois anos, frequência sistemática ao ambulatório, disposição para participar da pesquisa, tendo sido previamente esclarecidos os objetivos, a relevância do estudo e garantida a preservação do anonimato no momento em que concordavam em participar da pesquisa, por meio da assinatura do Termo de Consentimento Livre e Esclarecido. Ao todo, participaram do estudo 25 pacientes.

A coleta de dados foi realizada no período de maio de 2009 através de um formulário composto por perguntas fechadas e abertas. As informações foram organizadas e analisadas por meio de estatística descritiva e apresentadas em tabelas e gráficos, discutidas à luz da literatura pertinente. A pesquisa respeitou os preceitos éticos das pesquisas que envolvem seres humanos em conformidade à Resolução n ${ }^{0} 196 / 96$ do $\mathrm{CNS}^{7}$ e foi aprovada pelo Comitê de Ética em Pesquisa do hospital com o número 027.04.09.

\section{RESULTADOS}

Na tabela 1 são apresentados os dados referentes à identificação da amostra, o que permitiu caracterizar o paciente transplantado renal atendido pela instituição.

Conforme a tabela, a faixa predominante foi de pessoas do sexo masculino (68\%) em comparação com o sexo feminino (32\%), com faixa etária média entre 40 e 50 anos de idade (36\%), casados (12\%), com nível de escolaridade de 96\% (distribuídos entre níveis fundamental incompleto, fundamental completo e médio incompleto), cada um com $32 \%$. A renda média foi entre um e dois salários mínimos, características da população que mais frequenta o serviço público de saúde.

Tabela 1. Distribuição dos aspectos relacionados à identificação da amostra Fortaleza, 2009

\begin{tabular}{lll}
\hline Dados Pessoais e de identificação & $\mathbf{N}$ & $\%$ \\
\hline 1. Sexo & 17 & 68 \\
Masculino & 08 & 32 \\
Feminino & & \\
\hline
\end{tabular}

\section{Faixa etária}

$\begin{array}{lll}\text { Até } 30 \text { a } & 07 & 28 \\ 30 \neg r 40 a & 02 & 12 \\ 40\ulcorner 50 a & 09 & 36 \\ 50\ulcorner 60 a & 02 & 06 \\ >60 a & 01 & 0\end{array}$

\section{Estado Civil}

Casado

Solteiro

$12 \quad 8$

Outros

11

44

$02 \quad 08$

\section{Escolaridade}

$\begin{array}{lll}\text { Analfabeto } & 01 & 04 \\ \text { Fundamental incompleto } & 08 & 32 \\ \text { Fundamental completo } & 08 & 32 \\ \text { Médio completo } & 08 & 32\end{array}$

\begin{tabular}{lll}
\hline 5. Renda Familiar & & \\
$<1$ salário mínimo & 04 & 16 \\
1 a 2 salários mínimos & 18 & 72 \\
Mais de 2 salários & 03 & 12 \\
\hline Total & 25 & 100
\end{tabular}

O tempo de realização de hemodiálise antes do transplante pode ser visualizado através da figura 1.

Observou-se que 16 (64\%) dos pacientes realizavam hemodiálise há mais de cinco anos, oito (32\%) de um a cinco anos e um (4\%) há menos de um ano

$\mathrm{O}$ conhecimento dos pacientes em relação à utilização de medicamentos imunossupressores pode ser visualizado através da figura 2 . 
Figura 1. Distribuição do tempo em que o paciente renal leva realizando hemodiálise até o transplante - Fortaleza, 2009

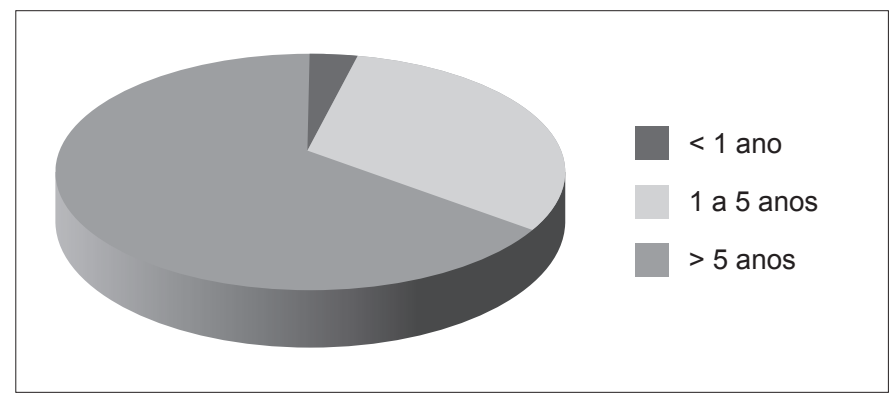

Figura 2. Distribuição dos pacientes renais em relação ao conhecimento sobre a importância do uso de drogas imunossupressoras - Fortaleza, 2009

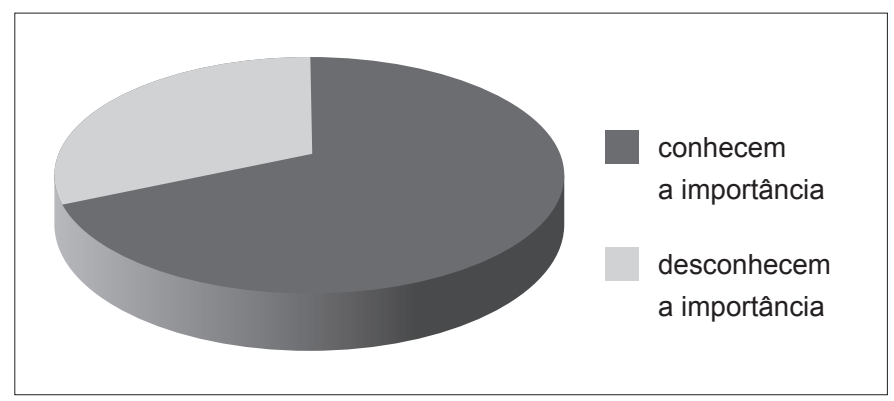

A figura 2 mostra que 17 (68\%) dos pacientes referiram conhecer a importância do uso de drogas imunossupressoras para manutenção adequada do enxerto e oito $(32 \%)$ desconheciam a importância dessas drogas. Com relação à qualidade de vida dos pacientes após o transplante renal, 24 (96\%) pacientes referiram melhora na qualidade de vida e apenas um (4\%) relatou que não houve melhora.

Discussão

Os dados epidemiológicos do estudo foram compatíveis com os encontrados por outros pesquisadores em relação ao sexo da maioria da amostra (masculino), faixa etária (em torno de 40 a 50 anos), escolaridade (predomínio do nível fundamental) e estado civil (casado/com companheiro) realizados na mesma instituição, o que demonstrou não ter havido mudança significativa no perfil dos pacientes atendidos no serviço, ao longo dos anos. ${ }^{8}$

A importância de se conhecer o perfil da amostra é defendida por estudiosos, os quais afirmam que a não adesão aos medicamentos imunossupressores em transplantados renais é muito frequente, e pode ser influenciada por vários fatores sócio-demográficos como idade, escolaridade e estado civil. ${ }^{9}$ Esses autores afirmam ainda que a não adesão é mais prevalente em pessoas jovens e solteiras. Com relação ao sexo e ao nível sócio-profissional, os estudos divergem, não havendo consenso.

Em sua maioria, os pacientes permaneceram em diálise por um período longo, acima de cinco anos. Esse fato é preocupante, pois os mesmos entram na fila de espera ainda jovens e em uma fase de vida produtiva. É importante que se estimule e promova novas habilidades, incluindo o desenvolvimento de atividades produtivas remuneradas ajustadas à sua nova condição, e, principalmente, à rotina de horários para as sessões de diálise. ${ }^{10}$
A fila de espera por um transplante é longa e a quantidade de doações ainda não consegue atender a essa demanda. Essa situação pode ser atribuída a vários fatores, como a dificuldade de detecção da morte encefálica, contra-indicações médicas, problemas na manutenção do potencial doador e recusa familiar em permitir a doação, ${ }^{11}$ em casos de doadores falecidos.

Porém, grande parte dos pacientes renais poderia ser beneficiada por um transplante com doador vivo. Segundo a Associação Brasileira de Transplante de Órgãos, ${ }^{12}$ o número de transplantes com doador falecido é cinco vezes maior que com doador vivo, o que caracteriza a falta de informação sobre a doação entre parentes de primeiro grau. Nesta pesquisa, o percentual de doadores falecidos correspondeu a $80 \%$ das doações.

Acredita-se que se faz necessário estimular campanhas educativas para a população com relação à doação de órgãos, também no que se refere ao doador vivo, a fim de contribuir para o aumento do número de doações entre parentes de primeiro grau.

A primeira opção de terapia renal substitutiva deveria ser o transplante renal com o doente sem ter realizado qualquer sessão de hemodiálise, porém, esse é um ideal. Outra questão é a estrutura de serviços para captação e doação de órgãos, uma vez que é de conhecimento geral que os doadores, em sua grande maioria, são familiares dos pacientes. ${ }^{13}$

Quanto ao uso de imunossupressores, apesar de a maioria conhecer sua importância, 28\% dos pacientes reconheceram já ter se esquecido de tomá-la pelo menos uma vez. Vale lembrar que a não adesão a essa medicação é reconhecida como um fator importante para o aumento de morbidade e mortalidade, redução na qualidade de vida, aumento dos custos médicos e excesso de utilização dos serviços de saúde, podendo ser uma causa direta de todos os insucessos de transplante e de todas as mortes. ${ }^{9}$

A quase totalidade da amostra referiu melhoria da qualidade de vida após o transplante; esse fato é atribuído à importância do funcionamento do enxerto, já que muitos deles conviveram com as limitações da hemodiálise. ${ }^{3}$

\section{CONCLUSÃO}

O estudo permitiu conhecer o perfil epidemiológico dos pacientes atendidos pelo ambulatório de transplante renal, o que é importante para nortear a assistência a essa clientela. Os médicos e enfermeiros devem estar conscientes da sua importância como educadores em saúde e promover uma assistência que ajude o paciente a compreender melhor o significado do procedimento, a importância da adesão ao tratamento, o uso correto de imunossupressores e o acompanhamento multiprofissional contínuo.

Infelizmente, percebe-se que o tempo entre o início da hemodiálise e o transplante renal ainda é longo, levando os pacientes a sofrer graves complicações da doença. Muitos deles poderiam beneficiarse da doação de órgãos de parentes próximos; entretanto, essa ainda não é a realidade, o que sugere pouca informação, medo e preconceitos por parte da família.

Observou-se que apesar de relatarem conhecer a importância do tratamento imunossupressor, alguns doentes esquecem-se de tomar os medicamentos, o que pode levar à rejeição do enxerto. Ainda assim, relataram melhoria da sua qualidade de vida após a realização do transplante, o que pode ser atribuído à maior liberdade em relação à hemodiálise. 


\section{ABSTRACT}

Introduction: Transplantation is the surgery performed in patients with serious and irreversible problem in an organ or tissue; he receives a healthy one from a living donor or one in brain death. It doesn't pose the cure, but possibility of a new life perspective that demands the adhesion to long term therapeutics, continue multi-professional follow-up and use of immunosuppressive medication. Purpose: To know the epidemic profile of patients assisted at a kidney transplantation clinic; check average waiting time on hemodialysis until the kidney transplantation in a reference hospital; investigate the knowledge of transplanted patients on the importance of using immunosuppressive medication. Methods: exploratory, descriptive research in quantitative approach carried out at a kidney transplantation clinic of a university hospital in the city of Fortaleza-Ceará-Brazil. The population was composed by 84 patients of both genders who received a kidney between January 2008 and April 2009. The sample was composed by 25 patients who fitted in the inclusion criteria. Data was collected after authorized by the Research Ethics Committee of Federal University of Ceará (UFC) through a questionnaire composed by open and closed questions and analyzed by tables and graphs. Results: There was no change in the profile of patients assisted by the clinic compared to previous studies, the time of waiting for transplantation is long, demanding the patient to remain in hemodialysis. Conclusion: The amount of living donor remains small (20\%), patients claim to know the importance of using immunosuppressive medication, although they not always follow the treatment with accuracy.

Keywords: Health Profile; Kidney Transplantation; Immunosuppressive Agents.

\section{REFERÊNCIAS}

1. I Reunião de diretrizes para captação e retirada de múltiplos órgãos e tecidos da Associação Brasileira de Transplantes de Órgãos (ABTO). São Paulo: ABTO; 2003.

2. Marinho A, Cardoso SS, Almeida VVC. Os transplante de órgãos nos Estados Brasileiros [Internet]. Rio de Janeiro; 2007. [citado em 2009 out 25]. Disponível em: http:/www.ipea.gov.br/sites/000/2/publicacoes/tds/td_1317.pdf.

3. Ravagnani LMB, Domingo NAM, Miyazaki COS. Qualidade de vida e estratégias de enfrentamento em pacientes submetidos a transplante renal. Estud Pscicol. 2007;12(2):177-84.

4. Bittencuort ZZLC, Alves Filho G, Mazzali M, Santos NR. Qualidade de vida em transplantados renais: importância do enxerto funcionante. Rev Saúde Pública. 2004;38(5):732-4.

5. Albuquerque JG, Lira ALBC, Lopes, MVO. Fatores preditivos e diagnósticos de enfermagem em pacientes submetidos a transplante renal. Rev Bras Enferm. 2010;63(1):98-103.

6. Maia BO, Amorim JS. Morte encefálica: conhecimento de acadêmicos de enfermagem e medicina. JBT J Bras Transpl. 2009;2:1088-91.

7. Conselho Nacional de Saúde. Resolução n. 196, de 10 de outubro de 1996. Dispõe sobre diretrizes e normas regulamentadoras de pesquisas envolvendo seres humanos.
Bioética. 1996;4(2 Suppl):15-25.

8. Lira ALC, Albuquerque JG, Oliveira MV. Perfil dos pacientes com transplante renal de um hospital universitário de Fortaleza-CE. Online Braz J Nurs. 2006 [periódico na Internet]; 5(1). [citado em 2010 set 22]. Disponível em: http://www.objnursing. uff.br/index.php/nursing/article/view/107/31

9. Telles-Correia D, Barbosa A I, Mega, Barroso E, Monteiro E. Adesão nos doentes transplantados. Acta Med Port. 2007;20:73-85.

10. Fernandes LF, Monteiro KCC, Lima JWO, Mesquita FMD, Pacheco MEAG. Salud y calidad de la vida de los pacientes en hemodiálisis. Psicol Am Lat [periódico na Internet]. 2009; 16. [citado em 2010 set 22]. Disponível em: http://pepsic.bvsalud. org/scielo.php?pid=S1870-350X2009000100008\&script=sci_arttext

11. Garcia VD. A política de transplantes no Brasil. Rev AMRIGS. 2006;50(4):313-20.

12. Associação Brasileira de Transplante de Órgãos. RBT Registro Brasileiro de Transplante Estatística de Transplante 2008 - Ano XIV, Nº 2 [Internet]. [citado em 2009 nov 20]. Disponível em: http// www.abto.org.br.

13. Cunha CB, Leon ACP, Schramm JMA, Carvalho MS, Souza Junior PRB, Chain R. Tempo até o transplante e sobrevida em pacientes com insuficiência renal crônica no estado do Rio de Janeiro, Brasil, 1998-2002. Cad Saúde Publica. 2007;23(4):805- 